\title{
Nitrogen Atom Detection in Low-Pressure Flames by Two-Photon Laser-Excited Fluorescence
}

\author{
J. Bittner, A. Lawitzki, U. Meier, and K. Kohse-Höinghaus \\ DLR-Institut für Physikalische Chemie der Verbrennung, Pfaffenwaldring 38-40, \\ W-7000 Stuttgart 80, Fed. Rep. Germany
}

Received 9 August 1990/Accepted 4 October 1990

\begin{abstract}
Nitrogen atoms have been detected in stoichiometric flat premixed $\mathrm{H}_{2} / \mathrm{O}_{2} / \mathrm{N}_{2}$ flames at 33 and 96 mbar doped with small amounts of $\mathrm{NH}_{3}, \mathrm{HCN}$, and $(\mathrm{CN})_{2}$ using two-photon laser excitation at $211 \mathrm{~nm}$ and fluorescence detection around $870 \mathrm{~nm}$. The shape of the fluorescence intensity profiles versus height above the burner surface is markedly different for the different additives. Using measured quenching rate coefficients and calibrating with the aid of known $\mathrm{N}$-atom concentrations in a discharge flow reactor, peak $\mathrm{N}$-atom concentrations in these flames are estimated to be on the order of $10^{12}-5 \times 10^{13} \mathrm{~cm}^{-3}$; the detection limit is about $1 \times 10^{11} \mathrm{~cm}^{-3}$.
\end{abstract}

PACS: $82.40 \mathrm{Py}, 33.50 \mathrm{Dq}$

In the combustion of nitrogen-containing fuels, a variety of conditions have been identified under which atomic nitrogen is of importance. For example, $\mathrm{N}$ atoms can influence the product distribution in the conversion of fuelbound nitrogen to $\mathrm{N}_{2}$ or $\mathrm{NO}_{x}$. Depending on the particular nitrogen source and the temperature and equivalence ratio of the combustion process, the reactions of $\mathrm{N}$ atoms with e.g. $\mathrm{OH}, \mathrm{NO}$, or $\mathrm{CH}_{3}$ can lead to the formation of $\mathrm{NO}, \mathrm{N}_{2}$, or $\mathrm{HCN}$. A detailed treatment of the gas-phase nitrogen chemistry in combustion can be found in the recent review by Miller and Bowman [1].

Nitrogen atom concentrations have been measured by ESR [2] and by atomic resonance absorption (ARAS) [3]. ESR spectroscopy has been used to detect $\mathrm{N}$ atoms in discharge flow reactors [2]. The ARAS technique requires vacuum $\mathrm{UV}$ radiation for the detection of $\mathrm{N}$ atoms; although it has proven most successful in shock tube experiments [3], flames usually are not transparent for these short wavelengths. Molecular beam sampling techniques coupled with mass spectrometry [4] were used in an investigation of the structure of a $45 \mathrm{mbar} \mathrm{NH}_{3} / \mathrm{O}_{2} / \mathrm{Ar}$ flame. In this experiment, $\mathrm{N}$ concentrations were found to be below the detection limit $\left(10^{-5}\right)$ of the apparatus throughout the flame. Their role in the kinetic mechanism was thus judged to be marginal [4]. The recent kinetic model of [1], however, predicts for this flame a mole fraction of $\mathrm{N}$ atoms which is about a factor of 30 higher than the upper limit stated in [4]. Upon addition of small amounts of $\mathrm{HCN}$ as $\mathrm{N}$-containing fuel to a 33 mbar $\mathrm{H}_{2} / \mathrm{O}_{2} / \mathrm{Ar}$ flame, Miller et al. [5] find that the
NO mole fraction is very sensitive to nitrogen atom reactions. Their conclusions on the importance of $\mathrm{N}$ atoms in the processes of $\mathrm{NO}$ formation and of conversion of $\mathrm{NO}$ to $\mathrm{N}_{2}$ under these conditions are in agreement with earlier work of Haynes [6] and Morley [7]. Although N atoms were not detected in their experiment, Miller et al. [5] predict $\mathrm{N}$ atom mole fractions of $5 \times 10^{-5}$ to $10^{-4}$ in their flames. In the context of these different flame studies, the experimental determination of $\mathrm{N}$ atom concentrations for specific combustion situations is expected to provide information which might be used to examine current chemical-kinetic models of the nitrogen chemistry in flames.

Two-photon laser-induced fluorescence is a non-perturbing optical diagnostic technique that provides excellent spatial resolution and sufficient sensitivity for the in-situ measurement of light atom concentrations under combustion-relevant conditions. Two-photon excitation of $\mathrm{N}$ atoms at about $211 \mathrm{~nm}$ and fluorescence detection at about $870 \mathrm{~nm}$ has been used in discharge flow reactor studies [8-11] to investigate collisional energy transfer out of and among the $\mathrm{N}\left(3 p^{4} D^{0}\right)$ manifold. A similar two-photon laser-excited fluorescence scheme has led to the detection of atomic nitrogen in atmospheric-pressure flames [12]. Various multi-photon excitation techniques have been used to detect hydrogen and oxygen atoms in flames [13-18]. In our group, we have recently developed a calibration method which allows spatially resolved measurements of $\mathrm{H}$ and $\mathrm{O}$ atom concentrations in low-pressure flames $[19,20]$. This method relies on 
a discharge flow reactor as a calibration standard: The two-photon laser-excited fluorescence signal arising from a known atom concentration produced in the flow reactor under identical excitation and detection conditions is related to the fluorescence signal produced by the unknown atom concentration at a particular location in the flame. Considering the different contributions of, in particular, collisional processes in both systems by solving the appropriate differential equations for the atomic levels involved, this calibration technique was capable of measuring $\mathrm{H}$ and $\mathrm{O}$ atom concentrations with a typical accuracy of $25 \%$ in low-pressure premixed $\mathrm{H}_{2} / \mathrm{O}_{2} / \mathrm{Ar}$ flames. In this paper we report an extension of this method to the quantitative detection of $\mathrm{N}$ atoms in flames.

This study aims at the spatially-resolved measurement of $\mathrm{N}$ atom concentrations in flat premixed low-pressure flames which might be suitable for a comparison with current modeling of the nitrogen chemistry. For this purpose, it seemed desirable to start from reasonably wellknown flame conditions as provided, for example, by the low-pressure $\mathrm{H}_{2} / \mathrm{O}_{2}$ flames studied in our group before [19-23]. Small amounts of $\mathrm{HCN},(\mathrm{CN})_{2}$, or $\mathrm{NH}_{3}$ were added as $\mathrm{N}$ atom precursors to $\mathrm{H}_{2} / \mathrm{O}_{2}$ flames diluted with $\mathrm{N}_{2}$. As the detailed nitrogen chemistry might be dependent on the nature of the additive, the shape of the $\mathrm{N}$ atom profile and the position of the local $\mathrm{N}$ atom concentration maximum was expected to be different for each additive.

\section{Experiment}

The main features of the experimental set-up were similar to the apparatus used before for the quantitative detection of $\mathrm{H}$ [19] and $\mathrm{O}$ atoms [20] in flames. A schematic of the experimental arrangement is given in Fig. 1.

Laser excitation was performed using the $\mathrm{N}\left(2 p^{3} S^{0}\right.$ $3 p^{4} D^{0}$ ) transition near $211 \mathrm{~nm}$. The third harmonic radiation at $355 \mathrm{~nm}$ of a Quanta Ray DCR-1 Nd:YAG laser was used to pump stilbene 3 in a Quanta Ray PDL-1 dye laser. (For some of the experiments, the DCR-1 was replaced by a DCR-4.) The alignment recommended by the manufacturer with transversely pumped oscillator, preamplifier, and amplifier stages yielded about $12 \mathrm{~mJ}$ at $422 \mathrm{~nm}$, about $30 \%$ of which was amplified spontaneous emission. Due to the short lifetime of the stilbene dye, the laser energy decreased by a factor of 2-3 during $6-10 \mathrm{~h}$

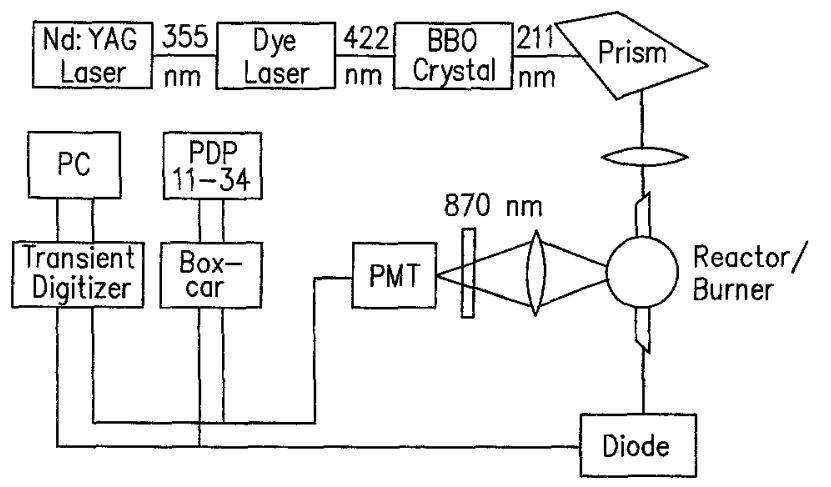

Fig. 1. Experimental arrangement of laser operation. Dye solutions were thus replaced up to three times a day.

The $420 \mathrm{~nm}$ laser beam was shaped by a long focal length telescope to an aproximately circular profile of $3.5 \mathrm{~mm}$ diameter at the entrance of a $4 \times 7 \mathrm{~mm}$ BBO crystal (CSK Corp., Los Angeles). The resulting frequencydoubled UV radiation at $211 \mathrm{~nm}$ was separated from the dye fundamental by a Pellin-Broca prism and directed into the discharge flow reactor or the low-pressure burner. Using different lens combinations, moderate laser power densities of typically $5 \times 10^{7} \mathrm{~W} \mathrm{~cm}^{-2}$ with beam sizes of $2-3 \times 10^{-4} \mathrm{~cm}^{2}$ resulted in the focal region. The laser pulse duration was measured with a fast photodiode to be $5.3 \mathrm{~ns}$. Pulse-to-pulse energy variations were $10-20 \%$. Considering the uncertainties in the measurement of pulse energies below $100 \mu \mathrm{J}$ and in the determination of the focal spot size, as well as the variation in laser energy associated with the rapid decay of the dye solution, the overall range of power density in the experiments was $2 \times 10^{7}-2 \times 10^{8} \mathrm{~W} \mathrm{~cm}^{-2}$, with a maximum variation of less than a factor of 2 within this range for an individual experiment. Similar power densities of about $5 \times 10^{7} \mathrm{~W} \mathrm{~cm}^{-2}$ were found suitable for avoiding photodissociative $\mathrm{O}$ atom production when measuring $\mathrm{O}$ atom concentrations in low-pressure $\mathrm{H}_{2} / \mathrm{O}_{2} / \mathrm{Ar}$ flames [20].

The fluorescence was monitored at right angles to the laser beam using the $\mathrm{N}\left(3 p^{4} D^{0}-3 s^{4} P\right)$ transition near $870 \mathrm{~nm}$ with an interference filter of $75 \%$ peak transmission and $8 \mathrm{~nm}$ FWHM centered at $871 \mathrm{~nm}$ (Hugo Anders, Nabburg, FRG). The fluorescence light was collected with a $f=100 \mathrm{~mm}$ lens. In this geometry, the length of the observation volume at the center of the burner was $5 \mathrm{~mm}$. A Hamamatsu R 636 photomultiplier supplied with $-1500 \mathrm{~V}$ and equipped with two fast preamplifiers $(400 \mathrm{MHz}, 7 \times$ amplification each) detected the fluorescence. With this photomultiplier/preamplifier combination, the temporal resolution was about $7.5 \mathrm{~ns}$. For quenching and calibration experiments, time-resolved fluorescence signals were monitored with a Tektronix R 7912 transient digitizer. Fluorescence intensity and laser intensity also were recorded with two fast gated integrators (Stanford Research Systems SR 250), with the gates set to the respective maxima of the laser and fluorescence pulses. In the flame experiments, the fluorescence was recorded with $20 \mathrm{~ns}$ gate width; in the flow reactor experiments, a gate width of $90 \mathrm{~ns}$ was used. Typically, 10 pulses were averaged in a particular experiment. A PDP $11 / 34$ computer and a CBM AT40/III personal computer which was interfaced to the gated integrators with a Stanford Research SR-245 computer interface controlled by the SR-267 data acquisition program were used for the control of the experimental as well as for data acquisition and evaluation.

For optimization and calibration purposes, a discharge flow reactor was used. Nitrogen atoms were produced by a microwave discharge in $\mathrm{N}_{2} / \mathrm{He}$ mixtures. The flow reactor was operated with $1000 \mathrm{sccm} \mathrm{He}(99.999 \%)$ and $80 \mathrm{sccm} \mathrm{N}_{2}(99.9995 \%)$ at typically $2-4$ mbar. For some quenching experiments, the pressure had to be increased to about 30 mbar to obtain significant changes in the effective lifetime. $\mathrm{N}$ atom concentrations of about 
Table 1. Flame conditions

\begin{tabular}{lllllllll}
\hline Flame & $\begin{array}{l}p \\
{[\mathrm{mbar}]}\end{array}$ & Additive & $\Phi$ & $\begin{array}{l}V_{\text {total }} \\
{[\mathrm{sccm}]}\end{array}$ & $\begin{array}{l}v_{273 \mathrm{~K}} \\
{\left[\mathrm{~cm} \mathrm{~s}^{-1}\right]}\end{array}$ & $x_{\mathrm{H}_{2}}$ & $x_{\mathrm{O}_{2}}$ & $x_{\mathrm{N}_{2}}$ \\
\hline I & 96 & $\mathrm{NH}_{3}$ & 1.0 & 2432 & 31 & 0.256 & 0.125 & 0.543 \\
II & 33 & $\mathrm{NH}_{3}$ & 1.0 & 2412 & 89 & 0.296 & 0.148 & 0.550 \\
III & 33 & $\mathrm{HCN}$ & 1.0 & 2412 & 89 & 0.296 & 0.148 & 0.550 \\
IV & 33 & $(\mathrm{CN})_{2}$ & 1.0 & 2412 & 89 & 0.296 & 0.148 & 0.550 \\
\hline
\end{tabular}

$p$ : pressure, $\Phi$ : equivalence ratio (corresponding to the undoped flame), $V_{\text {total }}$ : total gas flow, $v_{273 \mathrm{~K}}$ : cold flow velocity at $273 \mathrm{~K}, x:$ mole fraction

$10^{14} \mathrm{~cm}^{-3}$ were produced with an efficiency of the discharge of a few percent. By varying the pressure, wall recombination losses along the reactor tube were measured to be about $8 \%$. The $\mathrm{N}$ atom concentration in the flow reactor was determined by titration with NO which was added as a mixture of $10 \% \mathrm{NO}$ in $\mathrm{He}$ (Messer Griesheim). The small amounts of $\mathrm{NO} / \mathrm{He}$ mixture added for the titration changed the total flow by less than $1.5 \%$. The fast reaction of $\mathrm{NO}+\mathrm{N} \rightarrow \mathrm{O}+\mathrm{N}_{2}$ [24] is completed within the observation volume for all our flow conditions; secondary reactions are of negligible influence. $\mathrm{N}$ atom concentrations in the flow reactor could thus be determined with $2 \%$ accuracy.

The low-pressure burner has been described before [21]. Stoichiometric $\mathrm{H}_{2} / \mathrm{O}_{2} / \mathrm{N}_{2}$ flames were stabilized on a water-cooled porous plug with $42 \mathrm{~mm}$ active diameter. The flame conditions for the four flames studied in this investigation are listed in Table 1 . $\mathrm{HCN}$ and $(\mathrm{CN})_{2}$ were added as mixtures of $1 \%$ in $\mathrm{N}_{2}$ (Basi Technische Gase, Rastatt, FRG), $\mathrm{NH}_{3}$ was $99.995 \%$ (Deutsche LAir Liquide Edelgas $\mathrm{GmbH}$ ). The flame at $96 \mathrm{mbar}$ (flame I) was chosen because $\mathrm{OH}, \mathrm{H}$, and $\mathrm{O}$ concentrations and local temperatures have been measured before in very similar $\mathrm{H}_{2} / \mathrm{O}_{2}$ flames diluted with Ar instead of $\mathrm{N}_{2}$ [19-22]; very recently, the temperature profile has also been determined by $\mathrm{OH}$ laser-induced fluorescence and CARS in the undoped stoichiometric $\mathrm{H}_{2} / \mathrm{O}_{2} / \mathrm{N}_{2}$ flame at $96 \mathrm{mbar}$ [23]. At 33 mbar, the flames (II-IV) still can be regarded as nearly one dimensional, as determined by measuring radial concentration profiles, with the advantage that the $\mathrm{N}$ atom profile is spread out to a larger extent. In view of a recent discussion of potential catalytic effects of the burner surface on NO removal in NO-doped $\mathrm{H}_{2} / \mathrm{O}_{2}$ lowpressure flames [25], it is helpful for the interpretation of the current experiments that the flame is pushed away from the burner surface at 33 mbar.

Temperature is an essential quantity not only in the determination of absolute $\mathrm{N}$ atom concentrations from measured fluorescence signals but also for the chemicalkinetic modeling. Based upon the experience gained with different spectroscopic techniques under various flame conditions $[22,23,26]$, temperature profiles were measured using $\mathrm{OH}$ excitation spectra in the $(1,0)$ band as described before [23] with a typical accuracy of $2 \%$.

\section{Results and Discussion}

\subsection{Flow Reactor Experiments}

Excitation Spectrum. The upper trace (a) in Fig. 2 shows a two-photon excitation spectrum obtained in the dis-
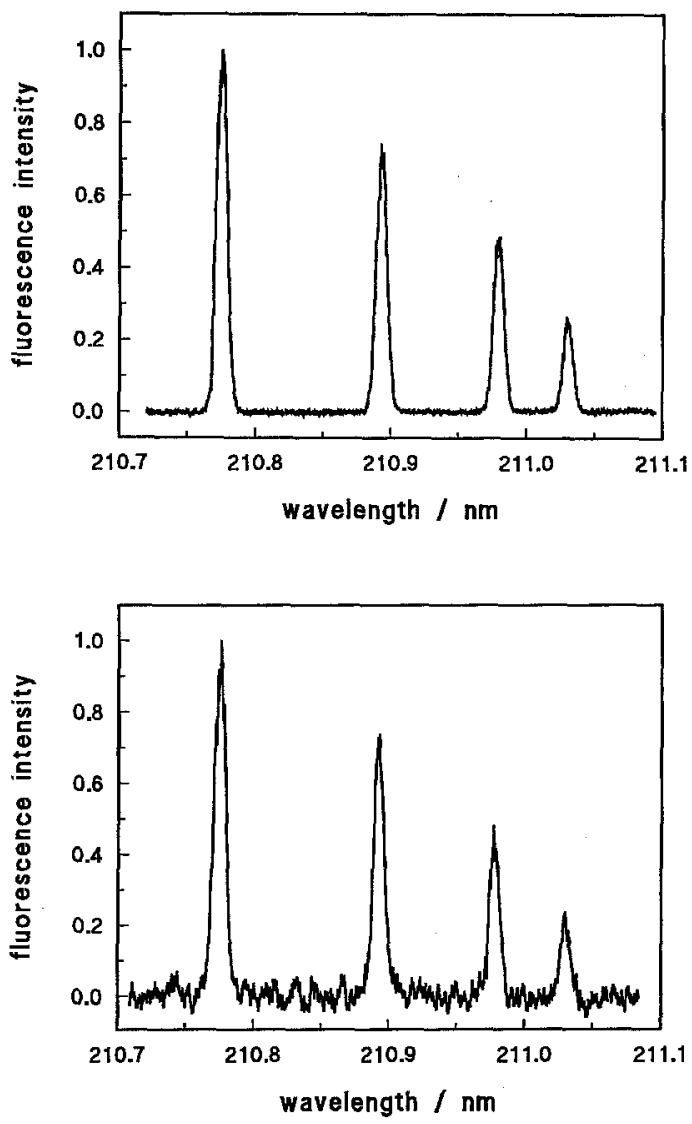

Fig. 2. $\mathrm{N}$ atom spectra in the flow reactor at $2 \mathrm{mbar}$ (upper trace) and in flame I (doped with $\mathrm{NH}_{3}$ ) at $3 \mathrm{~mm}$ above the burner surface (lower trace)

charge flow reactor at $2 \mathrm{mbar}$ in a mixture of $7 \% \mathrm{~N}_{2}$ in He. The spectrum exhibits the four allowed transitions from the $\mathrm{N}\left(2 p^{34} S^{0}\right)$ ground state to the $2 p^{2} 3 p^{4} D^{0}$ state. The observed intensity distribution of 4:3:2:1 $( \pm 2 \%)$ corresponds to the respective degeneracies of the $J=7 / 2$, $5 / 2,3 / 2$, and $1 / 2$ fine structure components of the ${ }^{4} D^{0}$ state, in agreement with earlier investigations [9]. The total fluorescence collected in this experiment can comprise eight allowed transitions (one from the $7 / 2$, two from the $5 / 2$, three from the $3 / 2$, and two from the $1 / 2$ fine structure level), for which the interference filter has approximately equal transmission. It is known [11] that rapid intramultiplet energy transfer can occur in the ${ }^{4} D^{0}$ state so that fine structure levels not originally excited by the laser may be populated. Reference [11] gives cross sections for the energy transfer with $\mathrm{N}_{2}$ as collision part- 


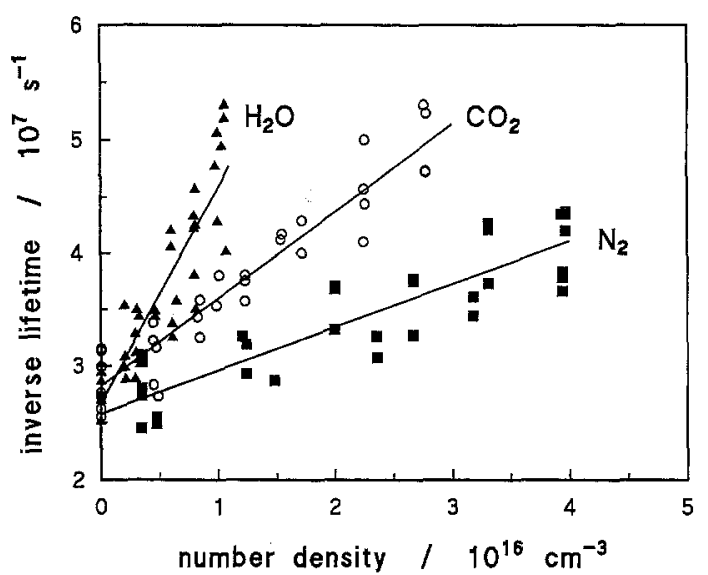

Fig. 3. Stern-Volmer plots (inverse effective lifetime vs number density of the collision partner) for quenching of $\mathrm{N}\left({ }^{4} D_{7 / 2}^{0}\right)$ by $\mathrm{H}_{2} \mathrm{O}, \mathrm{CO}_{2}$, and $\mathrm{N}_{2}$

Table 2. Quenching of $\mathrm{N}\left(3 p^{4} D_{7 / 2}^{0}\right)$ at $300 \mathrm{~K}$

\begin{tabular}{lll}
$\begin{array}{l}\text { Collision } \\
\text { partner }\end{array}$ & $\begin{array}{l}k_{\mathrm{Q}} / 10^{-10} \mathrm{~cm}^{3} \mathrm{~s}^{-1} \\
{[\text { this work] }}\end{array}$ & $\begin{array}{l}k_{\mathrm{Q}} / 10^{-10} \mathrm{~cm}^{3} \mathrm{~s}^{-1} \\
\text { Ref. [10] }\end{array}$ \\
\hline $\mathrm{He}$ & $<0.11 \pm 0.03$ & $<0.06$ \\
& $<0.13 \pm 0.01$ & \\
$\mathrm{Ar}$ & $1.13 \pm 0.08$ & $0.77 \pm 0.14$ \\
$\mathrm{~N}_{2}$ & $3.5 \pm 0.3$ & $4.6 \pm 0.6$ \\
& $4.1 \pm 0.4$ & \\
$\mathrm{H}_{2}$ & $8.0 \pm 1.0$ & \\
& $8.7 \pm 0.4$ & \\
$\mathrm{O}_{2}$ & $5.8 \pm 0.4$ & \\
& $5.7 \pm 0.3$ & \\
$\mathrm{H}_{2} \mathrm{O}$ & 18 & \\
& 21 & \\
$\mathrm{CO}$ & $13.4 \pm 2$ & \\
& $13.6 \pm 2.1$ & \\
$\mathrm{CO}_{2}$ & $7.5 \pm 0.9$ & \\
$\mathrm{CH}_{4}$ & $8.1 \pm 0.5$ & \\
\hline
\end{tabular}

ner. In our case, where helium is the dominant collision partner, intramultiplet energy transfer does not seem to influence the observed intensity distribution significantly.

As it provided the highest fluorescence signal, the ${ }^{4} D_{7 / 2}^{0}$ level was excited in all $\mathrm{N}$ atom detection experiments. Under our conditions, the resulting fluorescence intensity was not sensitive to the direction of the polarization of the laser, although polarization effects have been observed in experiments at similar pressures with nitrogen as bath gas [10]. It was found also in those experiments [27], however, in good agreement with our observation, that a few mbar of He scrambles the polarization rapidly while $\mathrm{N}_{2}$ may retain it.

Radiative Lifetime and Quenching. Since the calibration procedure involves measurements in two systems with different fluorescence quantum yields, information on the collisional removal rates and hence the effective decay rates is required to relate the fluorescence signals in flame and flow reactor. For this purpose, the decay time of the $\mathrm{N}$ atom fluorescence in the flow reactor at $300 \mathrm{~K}$ was measured for various collision partners. The relevant species which are present in the flames are $\mathrm{N}_{2}, \mathrm{H}_{2}, \mathrm{O}_{2}$, and $\mathrm{H}_{2} \mathrm{O}$; in addition, a rate coefficient for helium was measured since it was used as carrier gas in the flow reactor experiments. Figure 3 gives, as an example, Stern-Volmer plots for $\mathrm{H}_{2} \mathrm{O}, \mathrm{CO}_{2}$, and $\mathrm{N}_{2}$ as collision partners. Quenching of $\mathrm{N}$ atoms by $\mathrm{N}_{2}$ and rare gases has been studied by Copeland et al. [10]; to our knowledge, these are the only quenching data reported for $\mathrm{N}^{4} D^{0}$. Table 2 summarizes the quenching coefficients for $\mathrm{N}^{4} D_{7 / 2}^{0}$ measured in this investigation together with the data of Copeland et al. [10].

Each collisional deactivation rate was obtained from a least squares fit of the fluorescence decay to a single exponential function; typically, intervals from $90 \%$ to $10 \%$ of the fluorescence intensity were evaluated. Within experimental accuracy, no deviations from single-exponential behaviour could be observed. Therefore it seems unlikely that intramultiplet energy transfer contributes significantly to the measured collisional deactivation rates.

The radiative lifetime of the excited $\mathrm{N}$ atoms was determined from the intercept of the Stern-Volmer plots to be $39 \pm 3 \mathrm{~ns}$; the contribution of $\mathrm{He}$ and $\mathrm{N}_{2}$ necessary for the $\mathrm{N}$ atom production at zero number density of additional quencher was subtracted. The measured lifetime is in excellent agreement with the experimental result of Copeland et al. [10] $(43 \pm 3 \mathrm{~ns})$ as well as with a theoretical estimate of $37 \mathrm{~ns}$ [28]. Wiese et al. [29], however, give a substantially longer lifetime of $53 \mathrm{~ns}$ for this transition; the reason for this discrepancy is unclear.

The general agreement of the quenching coefficients from this work with the ones given in [10] is good. Our coefficient for quenching by $\mathrm{Ar}$ is about $40 \%$ higher than that of Copeland et al. [10], while our coefficient for quenching by $\mathrm{N}_{2}$ is $20 \%$ lower. The most efficient quencher for $\mathrm{N}\left({ }^{4} D_{7 / 2}^{0}\right)$ is the water molecule. This was alos noted for quenching of two-photon-excited $\mathrm{H}(3 s, 3 d)$ and $\mathrm{O}\left(3 p^{3} \mathrm{P}_{2,1,0}\right)$ atoms [30] where $\mathrm{H}_{2} \mathrm{O}$ had the largest quenching coefficient of various combustion-relevant collision partners. Most quenching coefficients for $\mathrm{N}$ atoms, with the exception of the one for $\mathrm{CO}$, are very similar in magnitude to the ones for $\mathrm{O}$ atoms, whereas $\mathrm{H}$ atoms are quenched about a factor 3-5 faster. The coefficient for quenching of $\mathrm{N}$ atoms by $\mathrm{CO}$ is quite high; a potential reason for this might be the efficient formation of an intermediate NCO complex.

Dependence of Fluorescence Intensity on Laser Power Density. The slope of a plot of the logarithm of the fluorescence intensity versus the logarithm of the laser power density is an important, although not sufficient, indication of the presence of interfering processes such as photodissociation or photoionization. Such effects can cause severe problems for the reliable determination of atom concentrations from two-photon-excited fluorescence signals; examples are given by a number of authors (see e.g. $[13,20]$, and shall not be repeated here.

Figure 4 shows the measured dependence of the fluorescence intensity on the laser power density for typical flow reactor conditions; the maximum laser power density corresponds to $1 \times 10^{8} \mathrm{~W} \mathrm{~cm}^{-2}$. The slope is close to 2 as expected for an unperturbed two-photon process. Photodissociation of molecular nitrogen which would yield 


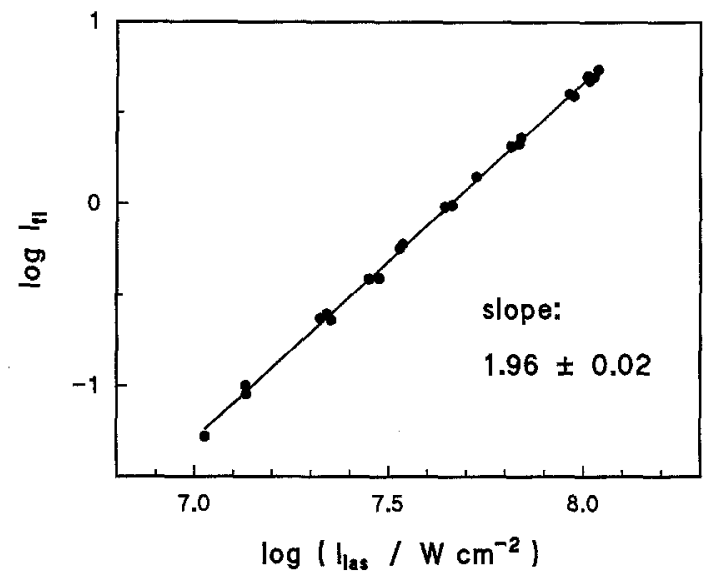

Fig. 4. Fluorescence intensity vs laser power density in the flow reactor at 33 mbar. Linear regression yields a slope of $1.96 \pm 0.02$

additional $\mathrm{N}$ atoms and which would cause a slope of $>2$ is unlikely under these conditions. The very small deviation from 2.0 might be due to photoionization which would deplete the excited state to a larger extent than radiative and collisional removal at increasing intensities and thus result in a slope of $<2$. Similar laser power densities were used for $\mathrm{N}$ atom detection in flames.

\subsection{Nitrogen Atom Detection in Flames}

The highest $\mathrm{N}$ atom fluorescence signal was found in the ammonia-doped flame at 96 mbar. The excitation spectrum measured in this flame is shown in the lower trace in Fig. 2. Again, the peak intensities correspond approximately (within 10\%) to the degeneracies for the four fine structure components. The signal-to-noise ratio is about a factor of 10 lower than in the flow reactor (compare with upper trace of Fig. 2) depending on the different $\mathrm{N}$ atom concentration and background emission in both systems.

Figure 5 shows the $\mathrm{N}$ atom fluorescence signal in this flame as a function of distance from the burner. The $\mathrm{N}$ atoms are present very close to the burner surface, as expected from preliminary flame model calculations [31]. In similar undoped flames the $\mathrm{OH}$ maximum occurs close to $10 \mathrm{~mm}$, and the $\mathrm{H}$ and $\mathrm{O}$ atom concentrations peak at about $4 \mathrm{~mm}$ [19-21]. In the first series of experiments, it was attempted to keep the base $\mathrm{H}_{2} / \mathrm{O}_{2} / \mathrm{N}_{2}$ flame constant with respect to stoichiometry, pressure, and cold flow velocity and to replace the $\mathrm{NH}_{3}$ additive by $\mathrm{HCN}$ or $(\mathrm{CN})_{2}$. However, at $96 \mathrm{mbar}$, we were not able to detect $\mathrm{N}$ atoms in flames doped with $\mathrm{HCN}$; in the $(\mathrm{CN})_{2}-$ doped flame, a potential $\mathrm{N}$ atom signal was completely obscured by a background fluorescence which was excited at the same wavelengths as the $\mathrm{N}$ quartet and which persisted throughout the first few $\mathrm{mm}$ above the burner surface. The molecule which causes this interference was not identified here; a more thorough measurement of its excitation and fluorescence spectrum would be necessary to reveal its identity.

When the pressure was reduced to $33 \mathrm{mbar}, \mathrm{N}$ atom profiles could be observed in a series of stoichiometric

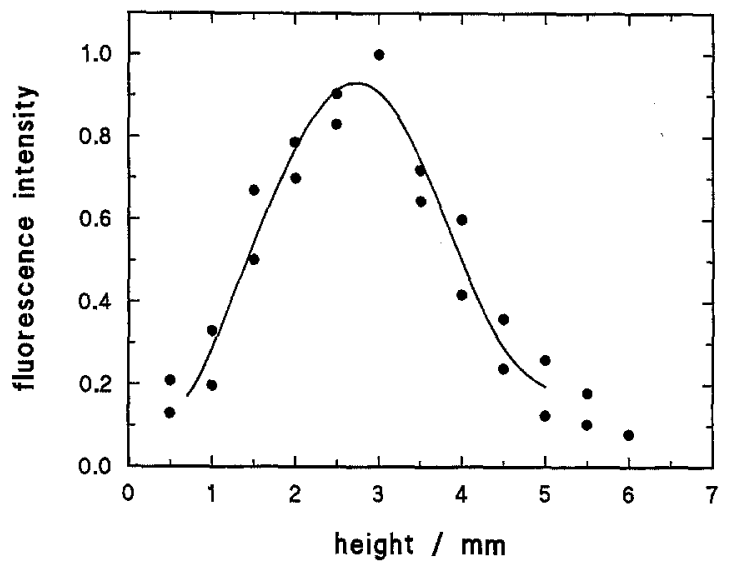

Fig. 5. $\mathrm{N}$ atom fluorescence intensity vs height above the burner surface in flame I. The maximum is arbitrarily scaled to 1.0
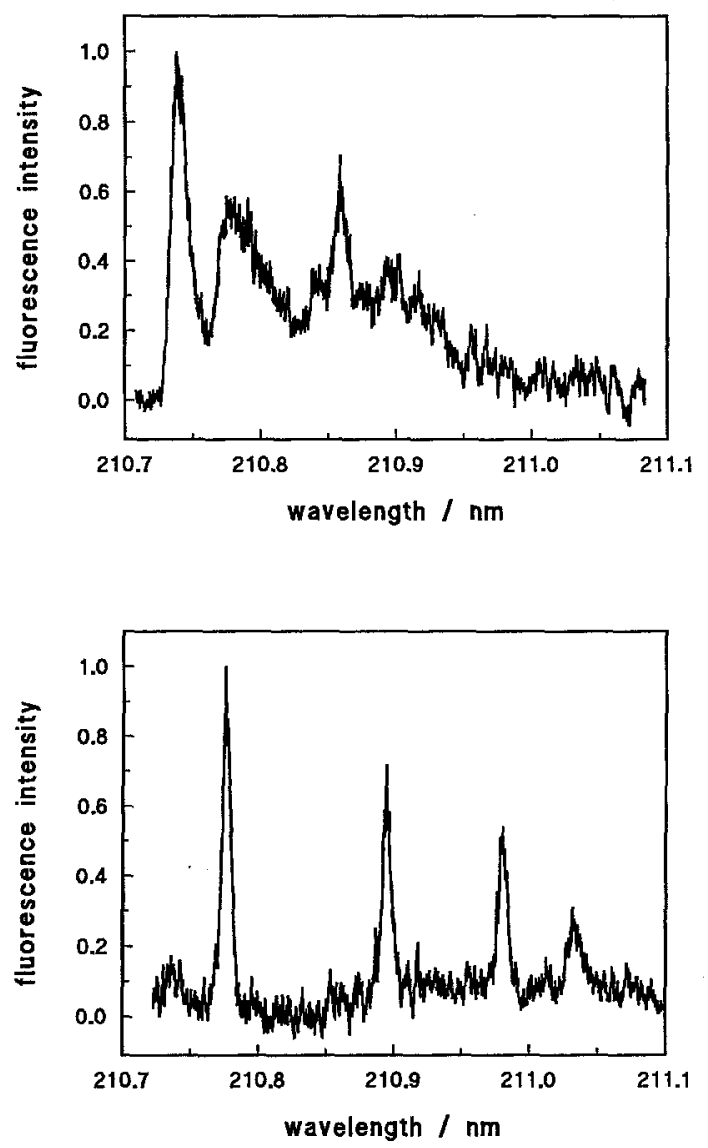

Fig. 6. $\mathrm{N}$ atom spectra in flame IV [doped with $(\mathrm{CN})_{2}$ ] at $1.5 \mathrm{~mm}$ (upper trace) and $5 \mathrm{~mm}$ (lower trace) above the burner surface

$\mathrm{H}_{2} / \mathrm{O}_{2} / \mathrm{N}_{2}$ flames doped with equal, very small mole fractions of $\mathrm{N}$-containing additives. The flame conditions are quite similar to the ones of Miller et al [5]. The excitation spectra which were measured in the 33 mbar flame doped with $(\mathrm{CN})_{2}$ (flame IV) at $1.5 \mathrm{~mm}$ and at $5 \mathrm{~mm}$ above the burner surface are shown in Fig. 6 . At $1.5 \mathrm{~mm}$, the $\mathrm{N}$ atom signal is completely obscured by the molecular background which was also observed in the flame at $96 \mathrm{mbar}$. At $5 \mathrm{~mm}$ above the burner surface, the $\mathrm{N}$ atom spectrum is clearly discernible from the background flu- 


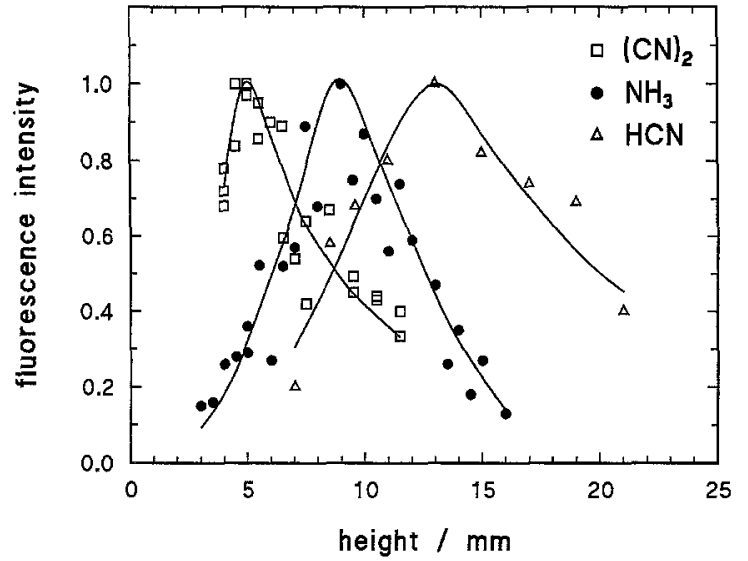

Fig. 7. $\mathrm{N}$ atom fluorescence intensity profiles vs height above the burner surface in flames II, III, and IV. The three profiles are scaled to a common maximum of 1.0

orescence. To avoid any ambiguity in the results, the $\mathrm{N}$ atom fluorescence intensity was recorded only at heights above $4 \mathrm{~mm}$.

Figure 7 summarizes the $\mathrm{N}$ atom fluorescence intensity profiles in the three stoichiometric $\mathrm{H}_{2} / \mathrm{O}_{2} / \mathrm{N}_{2}$ flames at 33 mbar (flames II-IV). The maxima are arbitrarily scaled to the common value of 1.0 . The fluorescence signal is strongest in the $(\mathrm{CN})_{2}$-doped flame. It should be noted, however, that twice the amount of nitrogen is added in this case, compared to flames II and III. The shape of the three fluorescence intensity profiles is clearly very different. In the $\mathrm{NH}_{3}$-doped flame at $33 \mathrm{mbar}$, the maximum of the $\mathrm{N}$ atom fluorescence intensity is found at about $9 \mathrm{~mm}$, compared to $3 \mathrm{~mm}$ in flame $\mathbf{I}$ at $96 \mathrm{mbar}$. The $\mathrm{N}$ atom profile in the flame with $(\mathrm{CN})_{2}$ additive peaks very close to the burner surface, at about $5 \mathrm{~mm}$, whereas the fluorescence intensity maximum in the $\mathrm{HCN}$-doped flame occurs comparatively late, at about $14 \mathrm{~mm}$. This markedly different behavior likely is the consequence of different chemical pathways for $\mathrm{N}$ atom formation and consumption in these three flames, which depend on the nature of the $\mathrm{N}$ atom precursor.

\subsection{Estimated Nitrogen Atom Concentrations}

Calibration Technique. In order to compare the $\mathrm{N}$ atom fluorescence profiles of Figs. 5 and 7 with flame model simulations, the fluorescence intensities have to be converted to number densities. If the calibration does not rely on additional information, as e.g. on the assumption of partial equilibria and known radical concentrations in the burnt gases, this procedure usually requires that the two-photon excitation rate, the laser power density, the observation volume and detection efficiency, as well as the fluorescence quantum yield, have to be known with good accuracy. Our method of calibration relates two systems, flame and flow reactor, in which - apart from the atom concentrations - only the fluorescence quantum yields are different. It therefore has the advantage of being independent of geometric factors and not very sensitive to the excitation rate and laser power density, since all of these quantities are identical for both systems.
Although this study will not provide an accurate determination of $\mathrm{N}$ atom concentrations in flames, the input parameters and the remaining difficulties of the calibration for the case of $\mathrm{N}$ atoms will be discussed. A first estimate of the $\mathrm{N}$ atom concentrations will be given.

Calibration. A series of calibration experiments has been performed. For this, the fluorescence intensities $I^{F}$ in the flame and $I^{\mathrm{R}}$ in the flow reactor have been measured and the $\mathrm{N}$ atom concentration in the flow reactor $N^{\mathrm{R}}$ has been determined by titration with NO. The atom concentration in the flame $N^{\mathrm{F}}$ then can be related to the known atom concentration in the flow reactor by

$N^{\mathrm{F}}=\left(I^{\mathrm{F}} / I^{\mathrm{R}}\right) N^{\mathrm{R}} C_{\mathrm{Q}}$.

$C_{\mathrm{Q}}$ is a calibration factor $\geq 1$ which considers the different collision environments in both systems and which may depend on the position in the flame. For a given calibration experiment, this factor $C_{Q}$ is the only unknown quantity. It describes the loss of fluorescence quantum yield in the flame in relation to the comparatively collision-free environment in the flow reactor. $C_{\mathrm{Q}}$ is obtained by solving the system of differential equations which comprises the relevant processes for the twophoton-excited fluorescence detection of $\mathrm{N}$ atoms [19, 20]; it is defined as the ratio of maximum populations in the excited level in the flow reactor, $N_{\mathrm{e}, \max }^{\mathrm{R}}$, and in the flame, $N_{\mathrm{e}, \max }^{\mathrm{F}}$ :

$C_{\mathrm{Q}}=N_{\mathrm{e}, \max }^{\mathrm{R}} / N_{\mathrm{e}, \max }^{\mathrm{F}}$.

In the case of $\mathrm{N}$ atoms, eight coupled differential equations describe the time-dependent populations in the $\mathrm{N}$ ${ }^{4} S^{0}$ ground state, the four ${ }^{4} D^{0}$, and the three ${ }^{4} P$ sublevels. The processes to be considered are, in particular, twophoton excitation, radiative decay, collisional quenching, and intramultiplet energy transfer. In addition, stimulated emission, photoionization, and photodissociation of $\mathrm{N}$-containing molecules may affect the calibration depending on the laser power density. A multitude of coefficients must be known for an exact solution of the complete system, most of which can only be estimated.

Bischel et al. [9] give an excitation cross section of $0.9 \times 10^{-27} \mathrm{~cm}^{4} \mathrm{~W}^{-1}$ for the $\mathrm{N}\left({ }^{4} S^{0}-{ }^{4} D^{0}\right)$ two-photon transition. This value depends on their measured - too short - lifetime of $27 \mathrm{~ns}$. The same paper [9] lists a twophoton excitation cross section for $\mathrm{O}$ atoms which was later redetermined by the same group [32] to be a factor of about 2 lower. Similarly, their cross section for $\mathrm{H}$ atoms [9] agrees with the calculated one of Lambropoulos [33] for $\mathrm{H}(3 d)$ excitation within a factor of 2 . We thus believe the two-photon excitation cross section of [9] to be accurate within a factor of about 3 .

Radiative decay rates for the different levels are tabulated by Wiese et al. [29]. It must be kept in mind, however, that the measured fluorescence lifetime extrapolated to zero pressure is about $30 \%$ shorter, in agreement with Copeland et al. [10].

Effective collisional decay rates $k_{\text {eff }}=1 / \tau_{\text {eff }}$ can be obtained directly from measured temporal decays of the fluorescence intensity. While our temporal resolution is sufficient to measure the effective lifetime $\tau_{\text {eff }}$ in the flow 
reactor, it is inadequate to determine $\tau_{\mathrm{eff}}$ in flame $\mathrm{I}$ at 96 mbar. In flames II-IV at $33 \mathrm{mbar}$, the fluorescence intensity was too low to measure its temporal decay with sufficient accuracy. The time-dependent fluorescence signal could only be obtained in the $(\mathrm{CN})_{2}$-doped flame at $5 \mathrm{~mm}$ above the burner surface, the position of maximum fluorescence intensity. The measured decay is, however, short enough to be significantly influenced by the temporal shape of the laser pulse and the time constant of the detection system. $k_{\text {eff }}$ must thus be extracted from the experimental time dependence by repeatedly solving the set of differential equations with varied values for the collisional decay rate until good agreement between experimental and calculated effective decay rate is obtained.

Quenching rates $k_{\mathrm{Q} \text {, eff }}^{T}$ for flame and flow reactor conditions also can be obtained by adding the individual contributions:

$k_{\mathrm{Q}, \text { eff }}^{T}=\Sigma_{i} k_{\mathrm{Q}, i}^{T} N_{i}$,

where $N_{i}$ is the number density of collider $i$ and $k_{\mathrm{O}, i}^{T}$ the rate coefficient for quenching of $\mathrm{N}$ atoms by species $i$ at temperature $T$. For flame conditions, the local temperature, the number densities of the relevant colliders (mainly $\mathrm{N}_{2}, \mathrm{H}_{2} \mathrm{O}, \mathrm{H}_{2}$, and $\mathrm{O}_{2}$ ) and the temperaturedependent quenching coefficients must be known to calculate $k_{\mathrm{Q}, \text { eff }}^{T}$. Furthermore, the effect of intramultiplet energy transfer must be considered. The individual cross sections for these processes are, however, known only for $\mathrm{N}_{2}$ as collision partner at $300 \mathrm{~K}$.

As mentioned before, several additional processes may influence the fluorescence signal which become increasingly important with increasing laser power density. In the present experiments, the power density was quite low so that significant contributions of stimulated emission, photoionization, or photodissociation are unlikely.

The cross section for photoionization out of the $\mathrm{N}$ $\left({ }^{4} D^{0}\right)$ state by $211 \mathrm{~nm}$ radiation is not known. In addition, it could be quite different for the four sublevels, as is the case for the $\mathrm{H}(3 s)$ and $(3 d)$ states [33], so that it is not clear whether ionization would occur mainly from the directly excited sublevel or from neighboring ones populated by collisions. For $\mathrm{H}$ and $\mathrm{O}$ atoms, the range of photoionization cross sections by the respective UV laser radiation is $10^{-19}-10^{-18} \mathrm{~cm}^{-2}[32,33]$. An upper limit for the net influence of photoionization in the $\mathrm{N}$ atom experiments is given by the measured dependence of the fluorescence intensity on the laser power density in the flow reactor (Fig. 4). By simulating the measured slope with the set of differential equations, a crude estimate of the photoionization cross section can be obtained; this procedure yields a range of $1-5 \times 10^{-19} \mathrm{~cm}^{-2}$.

Photodissociation of $\mathrm{N}$ precursors by the UV laser radiation is not believed to be a problem in the flow reactor where $\mathrm{N}_{2}$ is the only $\mathrm{N}$-containing molecule. In the flame, the N-containing additives could, in principle, be photodissociated; in particular, vibrationally excited states could provide additional photodissociative channels. A power dependence would reveal a significant influence of photodissociative $\mathrm{N}$ atom production. But as the fluorescence intensity and hence the dynamic range were too small, we were not able to measure this dependence in the flames. Regarding the shape of the $\mathrm{N}$ atom fluorescence intensity profiles in Figs. 5 and 7 with their pronounced initial slopes, it seems however unlikely that photodissociation plays a major role - if this were the case, the $\mathrm{N}$ atom profiles would be flatter at the outset.

From the above discussion it is evident that an accurate determination of the $\mathrm{N}$ atom concentration is not possible without a better knowledge of some of the relevant quantities addressed above. However, our method of calibration is not very sensitive to most of these parameters. For example it has been shown for typical $\mathrm{H}$ and $\mathrm{O}$ atom detection experiments $[34,20]$ that a variation of the laser power density, the two-photon excitation cross section, or the photoionization cross section by a factor of 5 changed $C_{\mathrm{Q}}$ by less than $25 \%$. Similarly, for a given $k_{\mathrm{Q} \text {,eff }}^{T}$, the respective calibration factors for $\mathrm{H}$ atoms and for O atoms differ only by about 30\% [34] although the two-photon excitation and ionization rates for the two atoms are markedly different. We thus expect a similar insensitivity of $C_{\mathrm{Q}}$ to these quantities as well as to the laser power density for the $\mathrm{N}$ atom experiments.

Results of the Calibration Experiments. If photodissociation can be neglected, a lower limit of the $\mathrm{N}$ atom concentrations can be obtained by assuming $C_{\mathrm{Q}}=1$ [see (1)]. Using this assumption provides us with a crude estimate of the order of magnitude of the $\mathrm{N}$ atom concentrations. Table 3 lists lower limits of the $\mathrm{N}$ atom concentrations determined this way from the measured fluorescence signals and the known $\mathrm{N}$ atom concentration in the flow reactor; they are given for the positions of the maximum $\mathrm{N}$ atom fluorescence intensities (compare with Figs. 5 and 7). Included in Table 3 are measured temperatures at specific positions in the flames. Assuming $C_{\mathrm{Q}}$ to be independent of position, the fluorescence intensity profiles can be scaled accordingly to yield $\mathrm{N}$ atom concentration profiles in their lower limit. We shall discuss the probable range of values for $C_{\mathrm{Q}}$ below to obtain a more realistic concentration estimate.

Temperature profiles have been measured for the flames with and without additives. As the mole fractions of the additives are quite small, especially in flames II-IV, the temperatures are similar to the ones in the undoped flames. For flame I with the largest mole fraction of additive, the temperature increase is slightly steeper than for the corresponding undoped $\mathrm{H}_{2} / \mathrm{O}_{2} / \mathrm{N}_{2}$ flame, and the temperatures in the flame zone are typically $50-60 \mathrm{~K}$ higher. Within experimental accuracy, the measured temperatures in flames II and III are indistinguishable from those in the undoped flame at $33 \mathrm{mbar}$. The temperature rise in the $(\mathrm{CN})_{2}$-doped flame IV is again more rapid than the one observed in the undoped flame; the temperatures are up to $200 \mathrm{~K}$ higher. This is not too surprising in spite of the small additive concentration as cyanogen flames are known to burn at considerably higher temperatures than flames with $\mathrm{H}$-containing fuels. In the undoped flame at $96 \mathrm{mbar}$, the temperature profile has been measured before [23] by comparing different spectroscopic techniques. Temperatures determined in flame II agree very a well with those obtained by Miller et al. [5] in a similar flame. 
Table 3. Flame temperatures and lower limits of $\mathrm{N}$ atom concentrations

\begin{tabular}{|c|c|c|c|c|c|c|}
\hline Flame & $\begin{array}{l}p \\
{[\mathrm{mbar}]}\end{array}$ & Additive & $\Phi$ & $\begin{array}{l}h \\
{[\mathrm{~mm}]}\end{array}$ & $\begin{array}{l}T \\
{[\mathrm{~K}]}\end{array}$ & $\begin{array}{l}N_{\mathrm{N}}^{\min } \\
{\left[10^{12} \mathrm{~cm}^{-3}\right]}\end{array}$ \\
\hline $\mathrm{H}_{2} / \mathrm{O}_{2} / \mathrm{N}_{2}$ & 96 & - & 1.0 & $\begin{array}{r}3 \\
5 \\
10 \\
15\end{array}$ & $\begin{array}{l}1140 \\
1260 \\
1390 \\
1430\end{array}$ & \\
\hline I & 96 & $\mathrm{NH}_{3}$ & 1.0 & $\begin{array}{r}3 \\
5 \\
10\end{array}$ & $\begin{array}{l}1200 \\
1330 \\
1420\end{array}$ & 21 \\
\hline $\mathrm{H}_{2} / \mathrm{O}_{2} / \mathrm{N}_{2}$ & 33 & - & 1.0 & $\begin{array}{r}5 \\
9 \\
14 \\
20\end{array}$ & $\begin{array}{r}540 \\
810 \\
1060 \\
1200\end{array}$ & \\
\hline II & 33 & $\mathrm{NH}_{3}$ & 1.0 & 9 & 810 & 0.66 \\
\hline III & 33 & $\mathrm{HCN}$ & 1.0 & 14 & 1060 & 0.81 \\
\hline IV & 33 & $(\mathrm{CN})_{2}$ & 1.0 & $\begin{array}{r}5 \\
9 \\
14\end{array}$ & $\begin{array}{r}710 \\
980 \\
1150\end{array}$ & 4.0 \\
\hline
\end{tabular}

$N_{\mathrm{N}}^{\min }$ : lower limit of the $\mathrm{N}$ atom concentration at the position of the maximum $\mathrm{N}$ fluorescence intensity

With the measured temperature profiles, the number densities of the stable constituents which dominate the collisional deactivation of $\mathrm{N}$ atoms can be obtained quite accurately from flame model simulations. Using the room temperature values for the quenching coefficients given in Table 2, the effective lifetime is estimated to be on the order of $2 \mathrm{~ns}$ in the flame at $96 \mathrm{mbar}$ and of 4-5ns in the flames at 33 mbar. Comparing the estimated decay rate to the measured fluorescence decay in flame IV at $33 \mathrm{mbar}$, it seems probable that at least one of the quenching coefficients decreases slightly with increasing temperature.

With similar effective quenching rates of 2 and $5 \times$ $10^{8} \mathrm{~s}^{-1}$, as found in $\mathrm{H}$ and $\mathrm{O}$ atom experiments, $C_{\mathrm{Q}}$ is approximately $1.5-2$ and $2-2.8$, respectively. Remembering that $C_{Q}$ is almost insensitive to quantities other than the effective collisional deactivation rate, it is quite probable that $C_{\mathrm{Q}}$ will be not much different in these $\mathrm{N}$ atom experiments. With this assumption, the maximum $\mathrm{N}$ atom concentration in flame I would be about $4-6 \times 10^{13} \mathrm{~cm}^{-3}$, in flame II about $1-1.3 \times 10^{12} \mathrm{~cm}^{-3}$, in flame III about $1.2-1.6 \times 10^{12} \mathrm{~cm}^{-3}$, and in flame IV about $6-8 \times 10^{12} \mathrm{~cm}^{-3}$.

Lacking more detailed information at present, we must assume in a first approximation that $C_{Q}$ is independent of position in the flame. In $\mathrm{H}_{2} / \mathrm{O}_{2} / \mathrm{Ar}$ flames at $96 \mathrm{mbar}$ and different stoichiometries, the effective quenching rate for $\mathrm{H}$ and $\mathrm{O}$ atoms is almost independent of position in the burnt gases and varies by about $25-40 \%$ in the flame front $[34,20]$. Two parameters of influence partly compensate each other to produce this behavior: With increasing temperature, the total density decreases but the number density of the most efficient collider $\mathrm{H}_{2} \mathrm{O}$ increases. Variations in $C_{\mathrm{Q}}$ of about $30 \%$ are expected for the $\mathrm{N}$ atoms which are present early in the flame.

Following the arguments outlined above, the $\mathrm{N}$ atom concentrations in the flames studied here are on the order of $10^{12}-5 \times 10^{13} \mathrm{~cm}^{-3}$, on average a factor of 2 higher than the lower limits determined with $C_{\mathrm{Q}}=1$; the un- certainty in these concentrations is estimated to be about a factor of 2 . The corresponding $\mathrm{N}$ atom mole fractions are on the order of a few ppm to about $100 \mathrm{ppm}$. The $\mathrm{N}$ atom detection limit in these flames is approximately $1 \times 10^{11} \mathrm{~cm}^{-3}$ or $\leq 1 \mathrm{ppm}$. The $\mathrm{N}$ atom concentrations are 2-4 orders of magnitude lower than $\mathrm{H}$ and $\mathrm{O}$ atom concentrations determined by similar techniques in stoichiometric $\mathrm{H}_{2} / \mathrm{O}_{2} / \mathrm{Ar}$ flames at 96 mbar $[19,20,34]$. This large difference in number density illustrates the difficulty of detecting $\mathrm{N}$ atoms in flames by two-photon-excited fluorescence.

The estimated $\mathrm{N}$ atom mole fractions of $3 \times 10^{-6}$ $10^{-4}$ agree quite well with the range predicted by Miller et al. [5]. Furthermore, simulations with a flame model [31] exhibit some close similarities in the calculated $\mathrm{N}$ atom profiles to the ones found in the experiments. In the flame doped with $(\mathrm{CN})_{2}$, the maximum of the $\mathrm{N}$ atom concentration occurs much closer to the burner surface than in the flame with HCN additive; in addition, the calculated shapes of the $\mathrm{N}$ atom profiles are very similar to the experimental ones. The range of $\mathrm{N}$ atom concentrations of up to $5 \times 10^{13} \mathrm{~cm}^{-3}$ predicted by these model calculations is also quite close to the values estimated from the experiments.

\section{Conclusions}

In this study, we have applied the method of two-photonexcited laser-induced fluorescence to measure for the first time $\mathrm{N}$ atom profiles in flat premixed low-pressure $\mathrm{H}_{2} / \mathrm{O}_{2} / \mathrm{N}_{2}$ flames. Relying on a calibration technique developed and demonstrated before for the quantitative detection of $\mathrm{H}$ and $\mathrm{O}$ atoms in similar flames $[19,20$, 34], we estimated peak $N$ atom concentrations for these flames of $10^{12}-5 \times 10^{13} \mathrm{~cm}^{-3}$ to within a factor of 2 . A more accurate determination of $\mathrm{N}$ atom concentrations requires a better knowledge of some important quantities such as two-photon excitation and photoionization rates 
and cross sections for collisional deactivation of excited $\mathrm{N}$ atoms at flame temperatures. It has been shown how these quantities enter the calibration; a sensitivity analysis of the $\mathrm{N}$ atom concentrations to these parameters is being performed.

Nitrogen atoms occur in the flame very close to the burner surface in mole fractions of a few ppm to about $100 \mathrm{ppm}$. The shape of the $\mathrm{N}$ atom profiles depends strongly on the nature of the additive, suggesting different chemical reaction sequences in the $\mathrm{N}$ atom formation and consumption mechanism. The concentrations and the shape of the profiles are in good qualitative agreement with flame model calculations [31]. A further analysis of the measured $\mathrm{N}$ atom profiles may contribute to a better understanding of some aspects in nitrogen combustion chemistry.

Acknowledgements. Professor C.T. Bowman, Stanford University, performed the initial kinetics calculations. His recommendation of suitable flame conditions for this investigation is gratefully acknowledged. We are grateful to Professor Th. Just for stimulating discussions and his continuous interest in this work. Also we would like to thank Mr. E. Grisebach for his skillful assistance during some of the experiments. This study was supported in part by the Stiftung Volkswagenwerk.

\section{References}

1. J.A. Miller, C.T. Bowman: Prog. Energy Combust. Sci. 15, 287 (1989)

2. A.A. Westenberg, N. de Haas: J. Chem. Phys. 40, 3087 (1964)

3. K. Thielen, P. Roth: 20th Symposium (International) on Combustion (The Combustion Institute, 1984) p. 685

D.F. Davidson, R.K. Hanson: Int. J. Chem. Kinetics (1990) to be published

4. J. Bian, J. Vandooren, P.J. van Tiggelen: 21st Symposium (International) on Combustion (The Combustion Institute, 1986) p. 953

5. J.A. Miller, M.C. Branch, W.J. McLean, D.W. Chandler, M.D. Smooke, R.J. Kee: 20th Symposium (International) on Combustion (The Combustion Institute, 1984) p.673

6. B.S. Haynes: Combust. Flame 28, 81, 113 (1977)

7. C. Morley: 17th Symposium (International) on Combustion (The Combustion Institute, 1981) p. 23

8. W.K. Bischel, B.E. Perry, D.R. Crosley: Chem. Phys. Lett. 82, 85 (1981)

9. W.K. Bischel, B.E. Perry, D.R. Crosley: Appl. Opt. 21, 1419 (1982)

10. R.A. Copeland, J.B. Jeffries, A.P. Hickman, D.R. Crosley: J. Chem. Phys. 86, 4876 (1987)
11. J.B. Jeffries, R.A. Copeland, D.R. Crosley: J. Chem. Phys. 91, 2200 (1989)

12. U. Westblom, S. Agrup, M. Aldén, P. Cederbalk: Poster presented at the 23rd Symposium (International) of the Combustion Institute, Orléans, France, July 1990

13. J.E.M. Goldsmith: 20th Symposium (International) on Combustion (The Combustion Institute, 1984) p. 1331; Opt. Lett. 10, 116 (1985); Appl. Opt. 26, 3566 (1987); 22nd Symposium (International) on Combustion (The Combustion Institute, 1988) p. 1403

14. J.T. Salmon, N.M. Laurendeau: Opt. Lett. 11, 419 (1986); Appl. Opt. 26, 2881 (1987); Combust. Flame 74, 221 (1988)

15. P.J.H. Tjossem, T.A. Cool: Chem. Phys. Lett. 100, 479 (1983)

16. K.C. Smyth, P.J.H. Tjossem: Appl. Phys. B 50, 499 (1990)

17. M. Aldén, H.M. Hertz, S. Svanberg, S. Wallin: Appl. Opt. 23, 3255 (1984)

18. U. Westblom, S. Agrup, M. Aldén, H.M. Hertz: Appl. Phys. B 50, 487 (1990)

19. J. Bittner, K. Kohse-Höinghaus, U. Meier, S. Kelm, Th. Just: Combust. Flame 71, 41 (1988)

20. U. Meier, J. Bittner, K. Kohse-Höinghaus, Th. Just: 22nd Symposium (International) on Combustion (The Combustion Institute, 1988) p. 1887

21. K. Kohse-Höinghaus, S. Kelm, U. Meier, J. Bittner, Th. Just: In: Complex Chemical Reaction Systems, ed. by J. Warnatz, W. Jäger (Springer, Berlin, Heidelberg 1987) p. 292

22. A. Lawitzki, R. Tirgrath, U. Meier, K. Kohse-Höinghaus, A. Jörg, Th. Just: Proceedings of the Joint Meeting of the German and Italian Sections of the Combustion Institute, Ravello, Italy, September 1989

23. A. Lawitzki, I. Plath, W. Stricker, J. Bittner, U. Meier, K. Kohse-Höinghaus: Appl. Phys. B 50, 513 (1990)

24. JPL Publications 87-41, California Institute of Technology (1987)

25. R.J. Cattolica, J.A. Cavolowsky, T.G. Mataga: 22nd Symposium (International) on Combustion (The Combustion Institute, 1988) p. 1165

26. K. Kohse-Höinghaus, U. Meier, B. Attal-Trétout: Appl. Opt. 29, 1560 (1990)

27. J.B. Jeffries: SRI International, Menlo Park, USA (private communication)

28. D.R. Bates, A. Damgaard: Philos. Trans. Roy. Soc. London Ser. A 242, 101 (1949)

29. W.L. Wiese, M.W. Smith, B.M. Glennon: "Atomic Transition Probabilities", NSRDS-NBS4, (US Government Printing Office, Washington 1966)

30. J. Bittner, K. Kohse-Höinghaus, U. Meier, Th. Just: Chem. Phys. Lett. 143, 571 (1988)

31. C.T. Bowman: Stanford University, Stanford, USA (private communication)

32. D.J. Bamford, L.E. Jusinski, W.K. Bischel: Phys. Rev. A 34, 185 (1986)

33. P. Lambropoulos: University of California, Los Angeles, USA (private communication)

34. J. Bittner: Ph.D Thesis, DLR/Universität Heidelberg, FRG (1989) 